Article

\title{
Field Induced Single Ion Magnetic Behaviour in Square-Pyramidal Cobalt(II) Complexes with Easy-Plane Magnetic Anisotropy
}

\author{
Amit Kumar Mondal *,+ ${ }^{\mathbb{D}}$, Arpan Mondal (D) and Sanjit Konar* \\ Department of Chemistry, Indian Institute of Science Education and Research Bhopal, Bhopal Bypass Road, \\ Bhauri, Bhopal 462066, Madhya Pradesh, India; arpan16@iiserb.ac.in \\ * Correspondence: amit.iiserb@gmail.com (A.K.M.); skonar@iiserb.ac.in (S.K.); Tel.: +91-755-669-2336 (S.K.) \\ + Present address: Department of Chemical and Biological Physics, Weizmann Institute of Science, \\ Rehovot 76100, Israel.
}

Received: 23 October 2018; Accepted: 24 January 2019; Published: 2 February 2019

\begin{abstract}
Two penta-coordinate $\mathrm{Co}^{\mathrm{II}}$ complexes with formulae $[\mathrm{Co}(14-\mathrm{TMC}) \mathrm{Cl}]\left(\mathrm{BF}_{4}\right)(\mathbf{1}, 14-\mathrm{TMC}=$ 1,4,8,11-Tetramethyl-1,4,8,11-tetraazacyclotetradecane) and [Co(12-TBC) Cl] $\left(\mathrm{ClO}_{4}\right) \cdot(\mathrm{MeCN})(2,12-\mathrm{TBC}$ $=1,4,7,10$-Tetrabenzyl-1,4,7,10-tetraazacyclododecane) were synthesized and characterized. Structural analysis revealed that ligand coordinates to the $\mathrm{CO}^{\mathrm{II}}$ centre in a tetradentate fashion and the fifth position is occupied by chloride ion and the geometries around $\mathrm{Co}^{\mathrm{II}}$ centres are best described as distorted square pyramidal. Detailed magnetic measurements disclose the presence of significant easy-plane magnetic anisotropy and field induced slow magnetic relaxation behaviours of the studied complexes. More insight into the magnetic anisotropy has been given using ab initio theory calculations, which agree well with the experimental values and further confirmed the easy-plane magnetic anisotropy.
\end{abstract}

Keywords: Cobalt(II); square-pyramidal; single ion anisotropy; slow magnetic relaxation

\section{Introduction}

Following the discovery of single-molecule magnet (SMM) behaviour in the well-known $\mathrm{Mn}_{12}$ compound, the number of multinuclear transition metal complexes extended rapidly to probe this phenomenon [1-3]. However, it was becoming difficult to control the anisotropy parameter $(D)$ in polynuclear transition metal clusters and, therefore, impeding the effort to search high temperature SMMs. Recently, molecules comprising a single paramagnetic lanthanide or actinide metal centre have been reported to exhibit slow magnetic relaxation behaviour at low temperatures [4-6]. The substantial efforts have been given for the development of both lanthanides based [7-10] and transition metal based [11-25] single ion magnets (SIMs). During last few years, the efforts to rationally manipulate the magnetic anisotropy of single ion magnets have been increased [12]. However, factors governing the zero-field splitting parameters ( $D$ and $E$ ) are not well understood and intricate control over magnetic anisotropy has remained one of the most difficult tasks. Cobalt(II) based complexes are the most interesting candidates among transition metal-based single-ion magnets due to their non-integer spin ground state, which decreases the probability of quantum tunnelling of magnetization (QTM) [26]. The first example of $\mathrm{Co}^{\mathrm{II}}$ SIM was a pentacoordinate system having square-pyramidal geometry with bis(imino)pyridine pincer ligand in conjunction with two isothiocyanate ligands [25]. Thereafter several $\mathrm{Co}^{\mathrm{II}}$ based complexes with various coordinate systems have been explored for showing the single ion magnetic behaviour [11-17,20-24,27-33].

Here we are particularly interested in preparing the low-coordinate Co ${ }^{\text {II }}$ SIMs by using the macrocyclic ligand as the magnetic anisotropy is enhanced because of the unrestricted 
orbital angular momentum [14]. The fascinating coordination chemistry of macrocyclic ligands 1,4,8,11-tetramethyl-1,4,8,11-tetraazacyclotetradecane (14-TMC) and 1,4,7,10-Tetrabenzyl-1,4,7,10tetraazacyclododecane) (12-TBC) (Figure 1) have been efficiently premeditated for the synthesis of mononuclear transition metal-based complexes [34-37]. In recent times, a variety of different TMC ligands [34,36] has been successfully used for the synthesis of $\mathrm{Ni}^{\mathrm{II}}$ complexes where the ligand is changed from a 12-membered to a 14-membered ring (i.e., 12-TMC to 14-TMC; 12-TMC = 1,4,7,10-tetramethyl-1,4,7,10-tetraazacyclododecane). From these studies it has been revealed that the ring size of the TMC ligands has significant influence on the geometric and electronic structures of the resulting complexes [34,36]. Both the TMC and TBC ligands have been elegantly exploited to stabilize low valent metal complexes [34,36]. The coordination chemistry of Co ${ }^{\mathrm{II}}(14-\mathrm{TMC})$ has been less explored compared with $\mathrm{Ni}^{\mathrm{II}}$ complexes and thus it is of interest to us. Recently, few examples of five-coordinate $\mathrm{Co}^{\mathrm{II}}(14-\mathrm{TMC})$ complexes have been reported in the literature for showing the field induced slow magnetic relaxation behaviours [38,39].
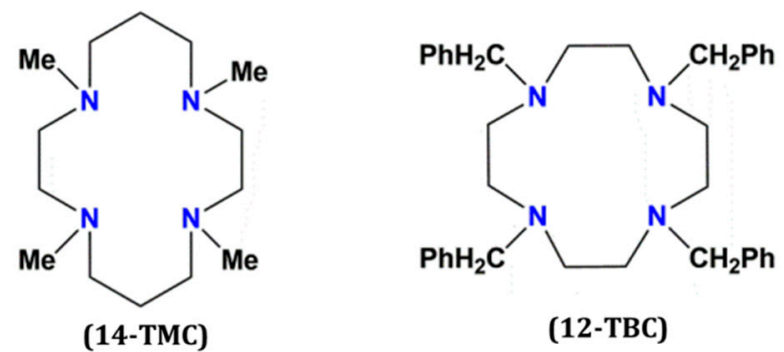

Figure 1. View of the structures of the tetradentate organic ligands 14-TMC (left) and 12-TBC (right) respectively (14-TMC =1,4,8,11-Tetramethyl-1,4,8,11-tetraazacyclotetradecane and 12 -TBC $=1,4,7,10$-Tetrabenzyl-1,4,7,10-tetraazacyclododecane).

Keeping the above points in mind and following our interest in Co ${ }^{\mathrm{II}}$ based SIMs $[16,17,20,21,24,27]$, we aimed to prepare low-coordinate $\mathrm{CO}^{\mathrm{II}}$ SIMs by using macrocyclic ligand 14-TMC and 12-TBC. Therefore in this paper we report the synthesis, structural characterization, and magnetization study of square-pyramidal $\mathrm{Co}^{\mathrm{II}}$ complexes $[\mathrm{Co}(14-\mathrm{TMC}) \mathrm{Cl}]\left(\mathrm{BF}_{4}\right)(\mathbf{1})$ and $[\mathrm{Co}(12-\mathrm{TBC}) \mathrm{Cl}]\left(\mathrm{ClO}_{4}\right) \cdot(\mathrm{MeCN})(\mathbf{2})$. Detailed magnetic measurements combined with theoretical studies disclose the presence of significant easy-plane magnetic anisotropy and field induced slow magnetic relaxation behaviours of $\mathbf{1}$ and 2.

\section{Results and Discussion}

The reaction of a mixture of two $\mathrm{Co}$ II salts $\left(\mathrm{CoCl}_{2}\right.$ and $\mathrm{Co}\left(\mathrm{BF}_{4}\right)_{2}$ for $1 ; \mathrm{CoCl}_{2}$ and $\mathrm{Co}\left(\mathrm{ClO}_{4}\right)_{2}$ for 2) with macrocyclic ligands (14-TMC and 12-TBC for 1 and 2 respectively) in a 1:1 molar ratio under ambient conditions gave complexes $\mathbf{1}$ and $\mathbf{2}$. The final reaction mixture was kept for crystallization and gave large $X$-ray-quality reddish brown crystals after three days. Single-crystal X-ray analysis revealed that complexes 1 and 2 crystallize in the monoclinic $P 2_{1}$ and $C 2 / c$ space groups respectively (See Supplementary Material Table S1). The molecular structures of $\mathbf{1}$ and $\mathbf{2}$ are shown in Figure 1. In both complexes, the geometry around the $\mathrm{CO}^{\mathrm{II}}$ centres are distorted square pyramidal where four nitrogen atoms (of macrocyclic ligand) are located in the basal plane of the pyramid and chloride ion is located at the axial position (Figure 2). Both 14-TMC and 12-TBC ligands coordinate to the metal centre in a tetradentate fashion and the geometries were further confirmed by the SHAPE analysis [40] with minimum CShM values of 0.558 and 0.846 for 1 and 2 respectively (Table S3). The macrocyclic ligands adopt the cis configuration with the four substituents directing towards the same side of macrocycle. For 1, Co ${ }^{\mathrm{II}}$ centre lies ca. $0.473 \AA$ out of the $\{\mathrm{N}(1), \mathrm{N}(2), \mathrm{N}(3), \mathrm{N}(4)\}$ plane in the direction of $\mathrm{Cl}(1)$. The values of trans positioned N-Co-N angles involving the nitrogen atoms of 14-TMC ligand are 162.74(6) and 146.43(5) ${ }^{\circ}$ for N2-Co1-N4 and N1-Co1-N3, respectively (See Supplementary Material Table S2). For $2, \mathrm{Co}^{\mathrm{II}}$ centre lies ca. $0.814 \AA$ A out of the $\{\mathrm{N}(2), \mathrm{N}(3), \mathrm{N}(4), \mathrm{N}(5)\}$ plane in the direction of $\mathrm{Cl}(2)$. 
The two trans positioned N-Co-N angles are almost identical 135.99(5) and 135.62(4) ${ }^{\circ}$ for N3-Co1-N5 and N2-Co1-N4, respectively, and correspond to the ideal spy geometry according to Addison et al. [40]. The geometry distortions of square pyramidal can be characterized using the $\tau$ parameter, defined as $(\alpha-\beta) / 60$ [41]. For 1 and 2 the $\tau$ values are 0.271 and 0.006 , respectively. In both the complexes, there are substantial intermolecular hydrogen-bonding interactions with counter anions $\left(\mathrm{BF}_{4}{ }^{-}\right.$and $\mathrm{ClO}_{4}{ }^{-}$for $\mathbf{1}$ and 2, respectively) and resulted in the formation of two-dimensional supramolecular arrangement (See Supplementary Material Figures S2-S5 and Tables S4 and S5). The solid-state packing diagram of $\mathbf{2}$ shows that the continuous 2D helical arrangement of interstitial lattice solvent molecules and perchlorate molecules along the crystallographic $a$ axis (Figure 3) and stabilized by several non-covalent interactions with each other.

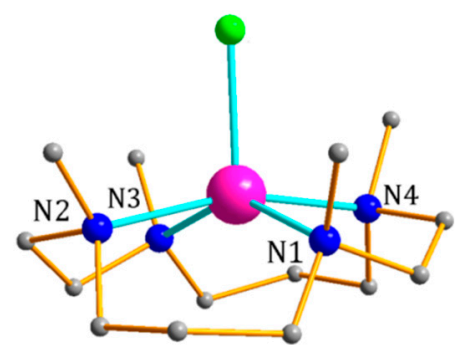

(a)

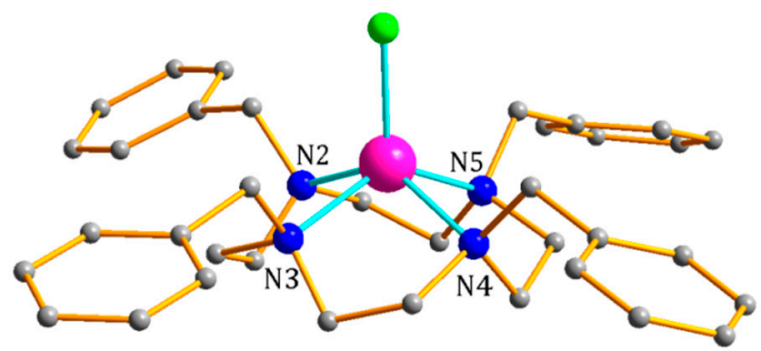

(b)

Figure 2. View of the molecular structures of complexes 1 (a) and 2 (b). Color codes: Co (magenta), $\mathrm{Cl}$ (green), $\mathrm{N}$ (blue), C (gray). Hydrogen atoms are omitted for clarity.

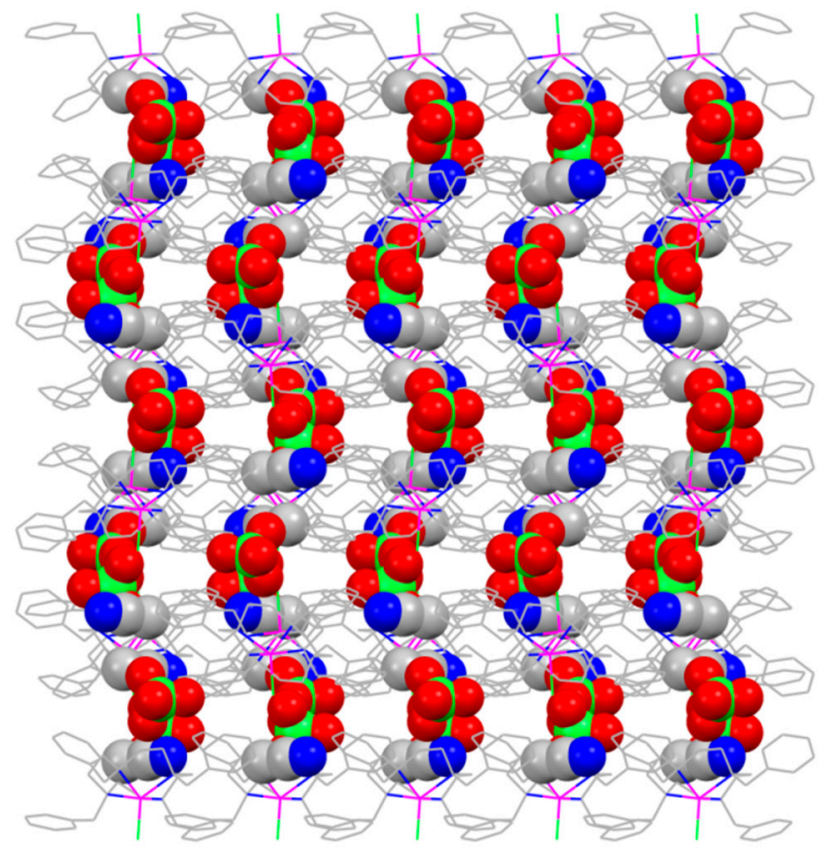

Figure 3. A view of packing diagram of complex 2 illustrating the continuous $2 \mathrm{D}$ helical arrangement of lattice solvent molecules and counter anions along the crystallographic $a$-axis.

Direct current (DC) magnetic susceptibility measurements have been performed under an applied field of 1000 Oe. $\chi_{\mathrm{M}} T$ values ( $\chi_{\mathrm{M}}=$ molar magnetic susceptibility) of 2.99 and $3.12 \mathrm{~cm}^{3} \mathrm{~K} \mathrm{~mol}^{-1}$ were obtained for $\mathbf{1}$ and 2, respectively, at room temperature and these values are larger than spin-only value of $1.875 \mathrm{~cm}^{3} \mathrm{~mol}^{-1} \mathrm{~K}$ for $S=3 / 2$ and $\mathrm{g}=2.00$ system. These values fall within the range of $2.1-3.4 \mathrm{~cm}^{3} \mathrm{~mol}^{-1} \mathrm{~K}$ for highly anisotropic $\mathrm{Co}^{\mathrm{II}}$ centers having orbital contribution [42]. Upon decreasing from $300 \mathrm{~K}$, the $\chi_{\mathrm{M}} T$ value gradually decreases and reached the minimum values of 1.77 and 
$1.98 \mathrm{~cm}^{3} \mathrm{~mol}^{-1} \mathrm{~K}$ for $\mathbf{1}$ and 2 respectively at $2 \mathrm{~K}$ (Figure 4a and Supplementary Material Figure S6). The magnetization data for 1 and 2 have been reached the highest values of 2.33 and $2.45 N \mu_{\mathrm{B}}$ respectively at $2 \mathrm{~K}$ and $7 \mathrm{~T}$ (Figure $4 \mathrm{~b}$ and Supplementary Material Figure S6). The magnetization values are lower than the theoretical saturation value for an $S=3 / 2$ system and also did not saturate at highest available fields. From the $M / \mathrm{N} \mu_{\mathrm{B}}$ vs. $H / T$ plots it can be found the presence of highly anisotropic systems for $\mathbf{1}$ and $\mathbf{2}$, as all isotherm magnetization plots did not fall on the same master curve (Figure S6). A spin Hamiltonian of Equation (1) has been described to quantify the magnetic anisotropy qualitatively:

$$
H=g \mu_{\mathrm{B}} S \cdot B+D\left[S_{\mathrm{z}}{ }^{2}-S(S+1) / 3\right]+E\left(S_{x}^{2}-S_{y}{ }^{2}\right)
$$

where $\mu_{\mathrm{B}}, S$ and $B$ terms represent the Bohr magneton, spin and magnetic field vectors, respectively; $D$ and $E$ terms represent single-ion axial and rhombic ZFS parameters. In order to calculate the ZFS parameters of $\mathrm{Co}^{\mathrm{II}}$ centres in 1-2, the PHI code [43] was used by concomitant fitting of the susceptibility and magnetization data and $g$ tensor was kept anisotropic during the fitting. The best fits gave $D=45.1(6) \mathrm{cm}^{-1}, E=9.9(1) \mathrm{cm}^{-1}$, and $\mathrm{g}_{\mathrm{x}}=2.29, \mathrm{~g}_{\mathrm{y}}=2.65, \mathrm{~g}_{\mathrm{z}}=1.98$ for $1 ; D=52.3(5) \mathrm{cm}^{-1}$, $E=10.1(7) \mathrm{cm}^{-1}$, and $\mathrm{g}_{\mathrm{x}}=2.66, \mathrm{~g}_{\mathrm{y}}=2.97, \mathrm{~g}_{\mathrm{z}}=2.02$ for 2 . Most of the reported pentacoordinate $\mathrm{CO}^{\mathrm{II}}$ SIMs are having square pyramidal or trigonal bipyramidal coordination geometries around $\mathrm{Co}^{\mathrm{II}}$ centres (Supplementary Material Table S6). It has been found that the obtained easy-plane magnetic anisotropies for the studied complexes agree well with the other previously reported square pyramidal $\mathrm{Co}^{\mathrm{II}}$ SIMs (Supplementary Material Table S6). The positive sign of $D$ parameter arises from the interaction between ground and excited electronic states coupled through spin-orbit coupling [16].

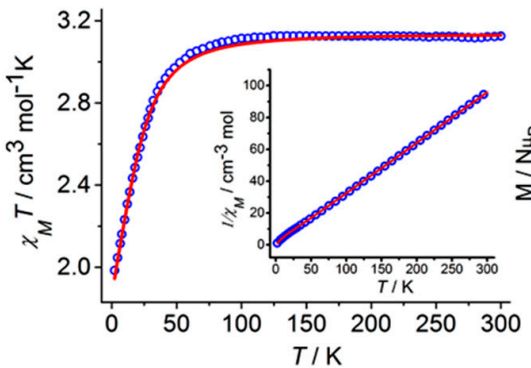

(a)

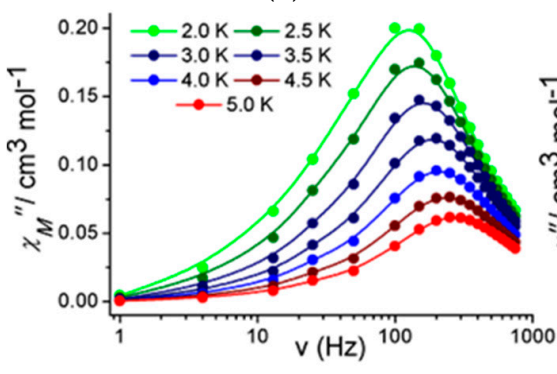

(d)

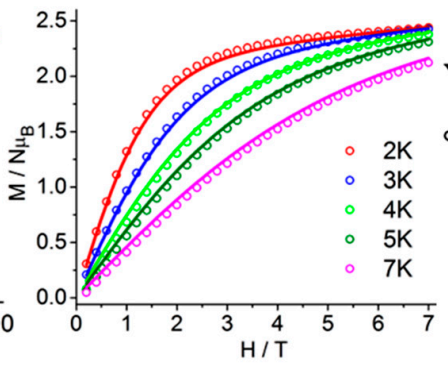

(b)

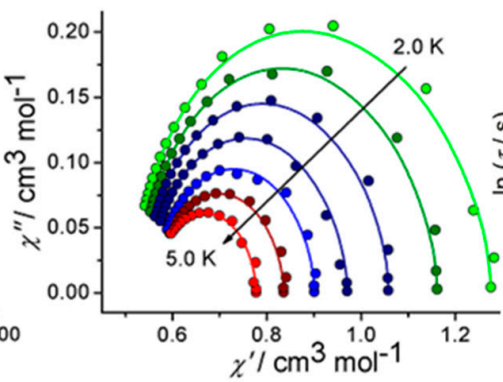

(e)

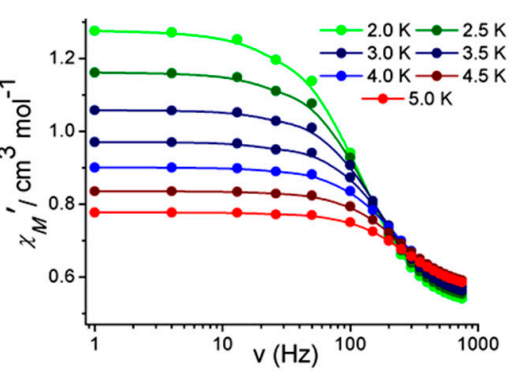

(c)

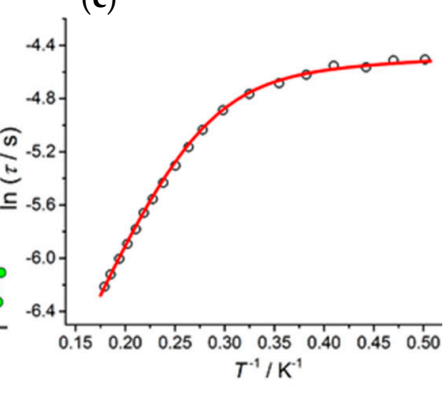

$(\mathbf{f})$

Figure 4. $\chi_{M} T$ vs. $T$ plots measured at $0.1 \mathrm{~T}$ for complex 2 (a). $1 / \chi_{M}$ vs. $T$ plots shown in the inset; $M / N \mu_{B}$ vs. $H$ plots for complex 2 (b) at the indicated temperatures. The solid lines are the best fit; Frequency dependency of the in-phase $\left(\chi_{M}{ }^{\prime}\right)(\mathbf{c})$ and out-of-phase $\left(\chi_{M}{ }^{\prime \prime}\right)(\mathbf{d})$ AC magnetic susceptibility plots for complex 2; Cole-Cole plots for complex 2 (e). Solid lines represent the best fit; Temperature dependency of the average relaxation time for complex 2 at $0.2 \mathrm{~T}$ dc field (f). The red line is the best fit obtained according to Equation (3).

More insight into the magnetic anisotropy of $\mathbf{1}$ and $\mathbf{2}$ was obtained using $a b$ initio theory calculations. The calculated $D$ and $E\left(\mathrm{~cm}^{-1}\right)$ and $\mathrm{g}$ values $(\mathrm{x}, \mathrm{y}, \mathrm{z})$ of $\mathbf{1}$ and $\mathbf{2}$ have been given in Table 1 . 
The calculated $D$ values of $\mathbf{1}$ and $\mathbf{2}$ are positive, and also agree well with the experimental values and further confirmed the easy-plane magnetic anisotropy for the studied complexes. Furthermore, from the splitting of the d orbital obtained from AILFT method [44] shows electronic transition between the different $\mathrm{m}_{1}$ values of the $\mathrm{d}$ orbital which results positive $D$ value (Figure 5 ). In the case of both complexes the $\mathrm{d}_{\mathrm{x} 2 \text {-y2 }}$ orbitals are relatively lower in energy. The metal ions reside above the plane containing four nitrogen atoms, thereby weakening the sigma bonding interaction with the four $\mathrm{N}$ donor atoms. Furthermore, due to the weak $\sigma$ donation from four $\mathrm{N}$ donor atoms and presence of $\pi$ donor $\mathrm{Cl}$ ligand this interacts with $\mathrm{d}_{\mathrm{xy}}$ orbital and enhancing the energy as compare to $\mathrm{d}_{\mathrm{x} 2-\mathrm{y} 2}$ orbital. Also, the higher energy gap between $\mathrm{d}_{\mathrm{xy}}$ and $\mathrm{d}_{\mathrm{x} 2 \text {-y2 }}$ orbitals results high positive $D$ value in complex 2 whereas for complex 1, those two orbitals are closer in energy leading more negative contribution and lowering the $D$ value. Other information like the orientation of computed $g$ tensor (Supplementary Material Figure S8), the energy of the first four excited states $\left(\mathrm{cm}^{-1}\right)$ and their contribution to the $D$ and $E$ values can be found in Table S7 which has been extracted from the ORCA calculations using the $a b$ initio ligand field theory (AILFT) method.

Table 1. Computed $D,|E|$ and $g_{x, y, z}$ values for the ground states of complexes $\mathbf{1}$ and $\mathbf{2}$.

\begin{tabular}{cccccc}
\hline Complex & $\boldsymbol{D}_{\text {expt }}\left(\mathrm{cm}^{-\mathbf{1}}\right)$ & $|E|_{\text {expt }}\left(\mathbf{c m}^{-\mathbf{1}}\right)$ & $D_{\text {calc }}\left(\mathrm{cm}^{-\mathbf{1}}\right)$ & $|E|_{\text {calc }}\left(\mathbf{c m}^{-\mathbf{1}}\right)$ & $\left(\mathrm{g}_{\mathrm{x}}, \mathrm{g}_{\mathrm{y}}, \mathrm{g}_{\mathrm{z}}\right)_{\text {cal }}$ \\
\hline $\mathbf{1}$ & $45.1(6)$ & $9.9(1)$ & 46.5 & 14.3 & $2.32,2.63,2.01$ \\
$\mathbf{2}$ & $52.3(5)$ & $10.1(7)$ & 49.1 & 11.2 & $2.70,2.90,1.99$ \\
\hline
\end{tabular}

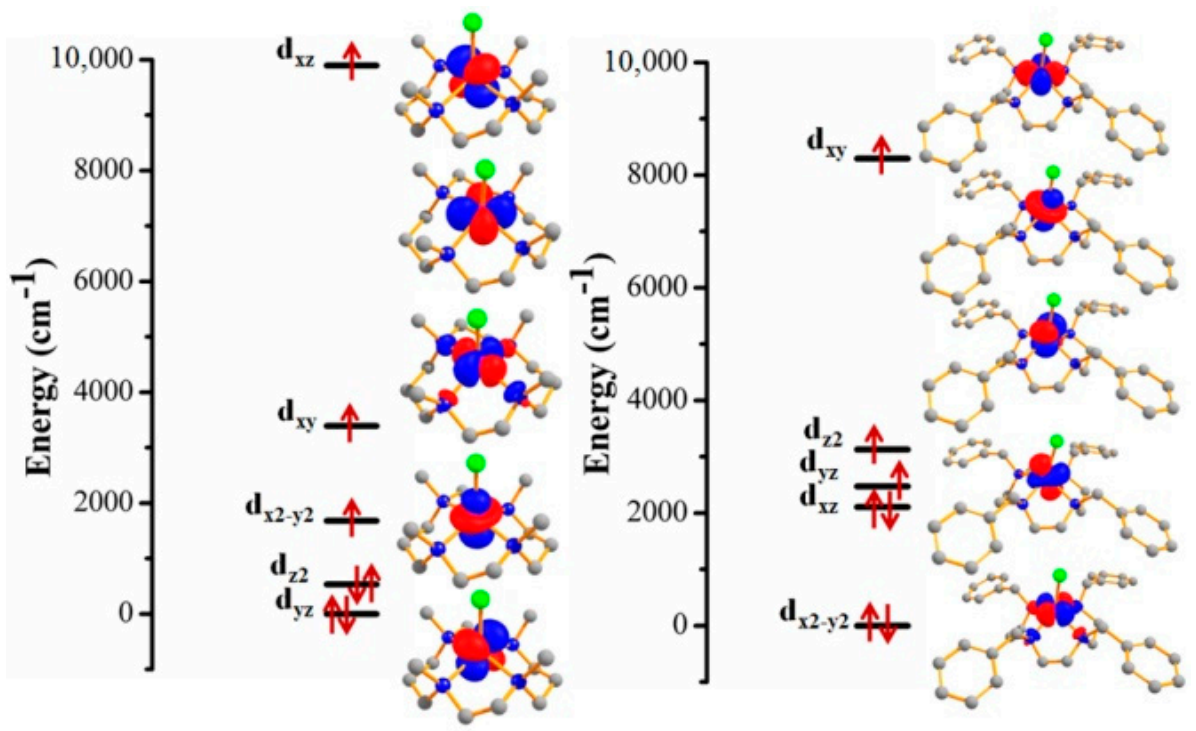

Figure 5. Ab initio ligand field theory (AILFT) computed d-orbital splitting of complexes $\mathbf{1}$ (left) and $\mathbf{2}$ (right). Orbital relative energies are given in $\mathrm{cm}^{-1}$.

In order to study the slow magnetic relaxation behaviours, ac susceptibility measurements were performed under 0 Oe dc field but complexes 1 and $\mathbf{2}$ didn't show frequency-dependent ac signal. The frequency-dependent ac signals were observed under a 2000 Oe dc field for both the complexes. However, for 1 the out-of-phase signals $\left(\chi_{\mathrm{M}}{ }^{\prime \prime}\right)$ do not show any peak maxima and therefore, the Debye model was used to estimate the energy barrier and relaxation time (Equation (2)) [45]. Best fitting gave the values of energy barrier $U_{\text {eff }}=7.3(6) \mathrm{K}$ and relaxation time $\tau_{0}=2.7 \times 10^{-6} \mathrm{~s}$ (Supplementary Material Figure S7) which agree well with the expected value of $10^{-6}-10^{-11}$ for a SMM [46-49].

$$
\ln \left(\chi^{\prime \prime} / \chi^{\prime}\right)=\ln \left(\omega \tau_{0}\right)+\mathrm{U}_{\mathrm{eff}} / k \mathrm{~T}
$$


For complex 2 the out-of-phase signals $\left(\chi_{M}{ }^{\prime \prime}\right)$ show peak maxima and therefore, the Cole-Cole plots [50] (Figure 4e) have been generated from the frequency-dependent ac susceptibility data. The generalized Debye model [51] has been used to fit the Cole-Cole plots and best fitting gave the values of $\alpha$ within the ranges of $0.05-0.29$. The curvature found in the $\ln (\tau)$ vs. $T^{-1}$ plot suggests the presence of other non-negligible relaxation processes along with the Orbach mechanisms in determining the relaxation rate (Figure 4f). Thus, the temperature dependence of $\tau$ can be well described by using Equation (3) including the contributions of QTM, Raman and Orbach mechanisms.

$$
\tau^{-1}=\tau_{\mathrm{QTM}}{ }^{-1}+C T^{n}+\tau_{0}{ }^{-1} \exp \left(-\mathrm{U}_{\mathrm{eff}} / k_{\mathrm{B}} T\right)
$$

The best fits were obtained giving $\mathrm{U}_{\text {eff }}=18.4(2) \mathrm{K}, \tau_{0}=3.2(5) \times 10^{-6} \mathrm{~s}, \tau_{\mathrm{QTM}}=1.43(7) \times 10^{-3} \mathrm{~s}$, $C=0.53(9) \mathrm{s}^{-1} \mathrm{~K}^{-5.8(9)}$ and $n=4.8$ (Figure $4 \mathrm{f}$ ). The $n$ value found to be very closer to the previously reported value for $\mathrm{Co}^{\mathrm{II}}-\mathrm{Y}^{\mathrm{III}}$ complex by Colacio et al. [52]. Thus, it has been found that along with the Orbach mechanisms the quantum tunnelling processes as well as the optical or acoustic Raman processes become also important to the overall relaxation process.

It has been found earlier that the difference in slow magnetic relaxation behaviours of mononuclear complexes was mostly because of the different structural distortions around the metal centres $[7,8,49,53-55]$. Therefore, in this present case the differences in ligand system between 1 and 2 brings the structural distortion and promote the elevation of $\mathrm{Co}^{\mathrm{II}}$ centre which, in turn, gives to substantial spin-orbit coupling and thus producing different anisotropic and dynamic behaviours.

\section{Materials and Methods}

All chemicals and ligands (14-TMC and 12-TBC) were commercially available and used without further purification. The elemental analyses were carried out on an Elementar Microvario Cube Elemental Analyzer. Magnetic measurements were performed using a SQUID VSM magnetometer (Quantum Design). The measured values were corrected for the experimentally measured contribution of the sample holder, while the derived susceptibilities were corrected for the diamagnetism of the samples, estimated from Pascal's tables [56].

Synthesis of [Co(14-TMC)Cl] $\left(\mathrm{BF}_{4}\right)(\mathbf{1})$ : A solution of $\mathrm{CoCl}_{2} \cdot 6 \mathrm{H}_{2} \mathrm{O}(12 \mathrm{mg}, 0.05 \mathrm{mmol})$ in $5 \mathrm{~mL}$ of $\mathrm{MeOH}$ was added to a solution of $\mathrm{Co}\left(\mathrm{BF}_{4}\right)_{2} \cdot 6 \mathrm{H}_{2} \mathrm{O}(17 \mathrm{mg}, 0.05 \mathrm{mmol})$ in $5 \mathrm{~mL}$ of MeOH. Then 14-TMC ligand $(26 \mathrm{mg}, 0.1 \mathrm{mmol})$ was dissolved in $\mathrm{MeCN}(10 \mathrm{~mL})$ was added dropwise to the previous solution. The reaction mixture was stirred at room temperature for $3 \mathrm{~h}$, filtrated, and the solution was allowed to evaporate to give large $\mathrm{X}$-ray-quality reddish brown crystals of $[\mathrm{Co}(14-\mathrm{TMC}) \mathrm{Cl}]\left(\mathrm{BF}_{4}\right)(\mathbf{1})$ after 3 days. The crystals were separated and washed with cold water and $\mathrm{Et}_{2} \mathrm{O}$; yield (71\%). Anal. Calcd for $\mathrm{C}_{14} \mathrm{H}_{32} \mathrm{ClCoN}_{4} \mathrm{~F}_{4} \mathrm{~B}: \mathrm{C}, 38.39 ; \mathrm{H}, 7.37 ; \mathrm{N}, 12.80 \%$. Found: $\mathrm{C}, 38.48 ; \mathrm{H}, 7.47 ; \mathrm{N}, 12.86 \%$. Selected IR data (KBr pellet, 4000-400 $\mathrm{cm}^{-1}$ ) v/ $\mathrm{cm}^{-1}: 2943\left(\mathrm{~s}, v_{\mathrm{C}-\mathrm{H}}\right), 1611\left(\mathrm{w}, v_{\mathrm{C}-\mathrm{C}}\right), 1456\left(\mathrm{~s}, v_{\mathrm{C}-\mathrm{N}}\right), 1269\left(\mathrm{~s}, v_{\mathrm{C}-\mathrm{N}}\right)$.

Synthesis of $[\mathrm{Co}(12-\mathrm{TBC}) \mathrm{Cl}]\left(\mathrm{ClO}_{4}\right) \cdot(\mathrm{MeCN})(2)$ : A solution of $\mathrm{CoCl}_{2} \cdot 6 \mathrm{H}_{2} \mathrm{O}(12 \mathrm{mg}, 0.05 \mathrm{mmol})$ in $5 \mathrm{~mL}$ of $\mathrm{MeOH}$ was added to a solution of $\mathrm{Co}\left(\mathrm{ClO}_{4}\right)_{2} \cdot 6 \mathrm{H}_{2} \mathrm{O}(18 \mathrm{mg}, 0.05 \mathrm{mmol})$ in $5 \mathrm{~mL}$ of $\mathrm{MeOH}$. Then 12-TBC ligand (53 mg, $0.1 \mathrm{mmol})$ was dissolved in $\mathrm{MeCN}(10 \mathrm{~mL})$ and was added dropwise to the previous solution. The reaction mixture was stirred at room temperature for $2 \mathrm{~h}$, filtrated, and the solution was allowed to evaporate to give large $\mathrm{X}$-ray-quality reddish brown crystals of $[\mathrm{Co}(12-\mathrm{TBC}) \mathrm{Cl}]\left(\mathrm{ClO}_{4}\right) \cdot(\mathrm{MeCN})(2)$ after 3 days. The crystals were separated and washed with cold water and $\mathrm{Et}_{2} \mathrm{O}$; yield (66\%). Anal. Calcd for $\mathrm{C}_{38} \mathrm{H}_{47} \mathrm{Cl}_{2} \mathrm{CoN}_{5} \mathrm{O}_{4}: \mathrm{C}, 59.44 ; \mathrm{H}, 6.17 ; \mathrm{N}, 9.13 \%$. Found: $\mathrm{C}$, $59.51 ; \mathrm{H}, 6.25 ; \mathrm{N}, 9.20 \%$. Selected IR data $\left(\mathrm{KBr}\right.$ pellet, 4000-400 $\left.\mathrm{cm}^{-1}\right) \mathrm{v} / \mathrm{cm}^{-1}: 2939\left(\mathrm{~s}, v_{\mathrm{C}-\mathrm{H}}\right), 1606(\mathrm{w}$, $\left.v_{\mathrm{C}-\mathrm{C}}\right), 1459\left(\mathrm{~s}, v_{\mathrm{C}-\mathrm{N}}\right), 1266\left(\mathrm{~s}, v_{\mathrm{C}-\mathrm{N}}\right)$.

Brüker APEX-II diffractometer was used for mounting suitable single crystals of 1-2 using Mo-K $\alpha$ $(\lambda=0.71073 \AA, 101 \mathrm{~K})$ radiation. $\varphi$ and $\omega$ scans were used for collection of raw data of each crystals. Direct methods were used for the solution of crystals using SHELXTL followed by full matric least square refinments against $\mathrm{F}^{2}$ [57]. The positions of the remanining non-hydrogen atoms were found by using difference Fourier synthesis and least square refinments. The exact crystal system, cell 
dimensions and orientation matrix were determined by the reported procedure followed by multi-scan absorption correction and Lorentx polarization. All H-atoms were calculated geometrically and refined using a riding model. The non-hydrogen atoms were refined with anisotropic displacement parameters. SHELXL 97 [58], PLATON 99 [59] and WinGXsystemVer-1.64 [60] were used for the refinement and calculations. The details of collection of data and their refinement parameters of 1-2 are listed in Table S1.

The calculation of the second-order magnetic anisotropy parameters ( $D$ and $E$ ) have been performed with ORCA 4.0 [61] on the experimentally determined X-ray structure without optimizations. In ORCA 4.0, CASSCF+NEVPT2 (Method of dynamic correlation effect) type calculation have been performed. Both the first principles and ZFS calculations have been done with scalar relativistic effect with ZORA (zeroth-order regular approximation) in ORCA. The following basis sets have been used: def2-TZVPP basis set for Co, def2-TZVP for $\mathrm{Cl}, \mathrm{N}$ and def2-SV(P) for other atoms. An auxiliary def $2 / \mathrm{JK}$ Coulomb fitting basis set was also used during the calculation. The quasi-degenerate perturbation theory (QDPT) approach has introduced the spin-orbit coupling effects. We have considered CAS $(7,5)$, where there are 7 electrons in 5 ' $d$ ' orbital, and computed 10 quartets and 40 doublets. In order to effect the dynamic correlation, we have employed N-electron valence perturbation theory (NEVPT2) on top of the CASSCF wave functions. The zero field splitting parameters were calculated from both the second order perturbation theory and an effective Hamiltonian approach (EHA).

\section{Conclusions}

In conclusion, two square-pyramidal $\mathrm{CO}^{\mathrm{II}}$ complexes have been synthesized and characterized. Detailed magnetic measurements combined with theoretical calculations of the studied complexes reveal the presence of significant easy-plane magnetic anisotropy and field induced slow magnetic relaxation behaviours. As a whole this work shows how the easy-plane magnetic anisotropy of square pyramidal $\mathrm{CO}^{\mathrm{II}}$ complex can be modulated by suitable variation of the ligand system. This leads to the conclusion that a careful choice of the organic ligand is thus necessary and may allow to control the geometry of mononuclear complexes and thus also their magnetic anisotropy.

Supplementary Materials: The following are available online at http:/ / www.mdpi.com/2312-7481/5/1/12/s1. Coordination polyhedral, SHAPE analysis table, magnetic plots, bond length and bond distances tables and hydrogen bonding tables. Figure S1: Distorted square-pyramidal coordination geometry around the $\mathrm{Co}^{\mathrm{II}}$ centers in 1 (left) and 2 (right), Figure S2: A view of supramolecular 2D arrangement of complex 1 through intermolecular H-bonding interactions, Figure S3: A view of packing diagram of complex 1 illustrating the continuous 2D arrangement of counter anions along the crystallographic a-axis, Figure S4: A view of supramolecular 2D arrangement of complex 2 through intermolecular H-bonding interactions, Figure S5: A view of packing diagram of complex 2 illustrating the continuous $2 \mathrm{D}$ arrangement of lattice solvent molecules and counter anions along the crystallographic $c$-axis, Figure S6: $\chi_{M} T$ vs. $T$ plots measured at $0.1 \mathrm{~T}$ for complex 1 (a). $1 / \chi_{M}$ vs. $T$ plots shown in the inset; $M / N \mu_{B}$ vs. $H$ plots for complex $1(\mathrm{~b})$ at the indicated temperatures. The solid lines are the best fit; $M / \mathrm{N} \mu_{\mathrm{B}}$ vs. $H / T$ plots at the indicated temperatures for complexes $\mathbf{1}(\mathrm{c})$ and $\mathbf{2}(\mathrm{d})$. The solid lines are the best fit, Figure S7: Temperature dependence of the out-of-phase $\left(\chi_{M}^{\prime \prime}\right)$ (left) AC magnetic susceptibility plots for complex 1 under 2000 Oe dc field; Natural logarithm of the ratio of $\chi_{M}$ " over $\chi_{M}^{\prime} v s .1 / T$ (right) for complex 1 (solid lines represent the best fit obtained from Equation (2) described in the main text), Figure S8: Orientation of the computed $g$ tensor for complexes 1 (left) and 2 (right) with ORCA; Table S1: X-ray Crystallographic Data and Refinement Parameters for complexes 1 and 2, Table S2: Bond distances $(\AA)$ and bond angles $\left(_{-}^{\circ}\right)$ around $\mathrm{Co}^{\mathrm{II}}$ centers found in complex 1 and 2, Table S3: Summary of SHAPE analysis for complexes 1-2, Table S4: H-bond parameters found in complex 1, Table S5: H-bond parameters found in complex 2, Table S6: Magnetic anisotropy (D parameter) and SIM parameters for previously reported pentacoordinate $\mathrm{Co}^{\mathrm{II}}$ single ion magnets (SIMs), Table S7: Energy of the first four excited states $\left(\mathrm{cm}^{-1}\right)$ and their contribution to the $D$ and $E$ values in $\mathrm{cm}^{-1}$ at CAS $(7,5)$ NEVPT2 level by ORCA.

Author Contributions: A.K.M. designed the project and performed all the experiments; A.K.M. solved the crystal structures and collected and analyzed the magnetic data; A.K.M. and A.M. wrote the paper; S.K. supervised the overall project.

Funding: A.K.M. thanks UGC for the PhD fellowship. A.M. thanks to IISER Bhopal for PhD fellowship. S.K. thanks DAE BRNS, 37(2)/14/09/2015/BRNS, Government of India and IISER Bhopal for generous financial and infrastructural support. 
Acknowledgments: The high-performance computing (HPC) facility at IISER Bhoapl is gratefully acknowledged for the computational work.

Conflicts of Interest: The authors declare no conflict of interest.

\section{References}

1. Caneschi, A.; Gatteschi, D.; Sessoli, R.; Barra, A.L.; Brunel, L.C.; Guillot, M. Alternating current susceptibility, high field magnetization, and millimeter band EPR evidence for a ground $S=10$ state in $\left[\mathrm{Mn}_{12} \mathrm{O}_{12}\left(\mathrm{Ch}_{3} \mathrm{COO}\right)_{16}\left(\mathrm{H}_{2} \mathrm{O}\right)_{4}\right] \cdot 2 \mathrm{CH}_{3} \mathrm{COOH} \cdot 4 \mathrm{H}_{2} \mathrm{O}$. J. Am. Chem. Soc. 1991, 113, 5873-5874. [CrossRef]

2. Sessoli, R.; Tsai, H.L.; Schake, A.R.; Wang, S.Y.; Vincent, J.B.; Folting, K.; Gatteschi, D.; Christou, G.; Hendrickson, D.N. High-spin molecules: $\left[\mathrm{Mn}_{12} \mathrm{O}_{12}\left(\mathrm{O}_{2} \mathrm{CR}\right)_{16}\left(\mathrm{H}_{2} \mathrm{O}\right)_{4}\right]$. J. Am. Chem. Soc. 1993, 115, 1804-1816. [CrossRef]

3. Brechin, E.K.; Wernsdorfer, C.W.; Yoo, J.; Yamaguchi, A.; Saňudo, E.C.; Concolino, T.R.; Rheingold, A.L.; Ishimoto, H.; Hendrickson, D.N.; Christou, G. Quantum Tunneling of Magnetization in a New $\left[\mathrm{Mn}_{18}\right]^{2+}$ Single-Molecule Magnet with $S=13$. J. Am. Chem. Soc. 2002, 124, 9710-9711. [CrossRef] [PubMed]

4. Dey, A.; Kalita, P.; Chandrasekhar, V. Lanthanide(III)-Based Single-Ion Magnets. ACS Omega 2018, 3, 9462-9475. [CrossRef]

5. Woodruff, D.N.; Winpenny, R.E.P.; Layfield, R.A. Lanthanide Single-Molecule Magnets. Chem. Rev. 2013, 113, 5110-5148. [CrossRef] [PubMed]

6. Goswami, S.; Mondal, A.K.; Konar, S. Nanoscopic molecular magnets. Inorg. Chem. Front. 2015, 2, 687-712. [CrossRef]

7. Goodwin, C.A.P.; Ortu, F.; Reta, D.; Chilton, N.F.; Mills, D.P. Molecular magnetic hysteresis at 60 kelvin in dysprosocenium. Nature 2017, 548, 439-442. [CrossRef]

8. Guo, F.-S.; Day, B.M.; Chen, Y.-C.; Tong, M.-L.; Mansikkamäki, A.; Layfield, R.A. A Dysprosium Metallocene Single-Molecule Magnet Functioning at the Axial Limit. Angew. Chem. Int. Ed. 2017, 56, 11445-11449. [CrossRef]

9. Rinehart, J.D.; Long, J.R. Exploiting single-ion anisotropy in the design of f-element single-molecule magnets. Chem. Sci. 2011, 2, 2078-2085. [CrossRef]

10. Meng, Y.-S.; Jiang, S.-D.; Wang, B.-W.; Gao, S. Understanding the Magnetic Anisotropy toward Single-Ion Magnets. Acc. Chem. Res. 2016, 49, 2381-2389. [CrossRef]

11. Craig, G.A.; Murrie, M. 3d single-ion magnets. Chem. Soc. Rev. 2015, 44, 2135-2147. [CrossRef] [PubMed]

12. Gómez-Coca, S.; Aravena, D.; Morales, R.; Ruiz, E. Large magnetic anisotropy in mononuclear metal complexes. Coord. Chem. Rev. 2015, 289, 379-392. [CrossRef]

13. Habib, F.; Luca, O.R.; Vieru, V.; Shiddiq, M.; Korobkov, I.; Gorelsky, S.I.; Takase, M.K.; Chibotaru, L.F.; Hill, S.; Crabtree, R.H.; et al. Influence of the Ligand Field on Slow Magnetization Relaxation versus Spin Crossover in Mononuclear Cobalt Complexes. Angew. Chem. Int. Ed. 2013, 52, 11290-11293. [CrossRef] [PubMed]

14. Bar, A.K.; Pichon, C.; Sutter, J. Magnetic anisotropy in two- to eight-coordinated transition-metal complexes: Recent developments in molecular magnetism. Coord. Chem. Rev. 2016, 308, 346-380. [CrossRef]

15. Woods, T.J.; Ballesteros-Rivas, M.F.; Gómez-Coca, S.; Ruiz, E.; Dunbar, K.R. Relaxation Dynamics of Identical Trigonal Bipyramidal Cobalt Molecules with Different Local Symmetries and Packing Arrangements: Magnetostructural Correlations and ab inito Calculations. J. Am. Chem. Soc. 2016, 138, 16407-16416. [CrossRef] [PubMed]

16. Mondal, A.K.; Jover, J.; Ruiz, E.; Konar, S. Investigation of easy plane magnetic anisotropy in P-ligand square-pyramidal Co ${ }^{\mathrm{II}}$ single ion magnets. Chem. Commun. 2017, 53, 5338-5341. [CrossRef] [PubMed]

17. Mondal, A.K.; Sundararajan, M.; Konar, S. A new series of tetrahedral Co(II) complexes $[$ CoLX 2$](X=\mathrm{NCS}$, Cl, Br, I) manifesting single-ion magnet features. Dalton Trans. 2018, 47, 3745-3754. [CrossRef] [PubMed]

18. Mathonière, C.; Lin, H.-J.; Siretanu, D.; Clérac, R.; Smith, J.M. Photoinduced Single-Molecule Magnet Properties in a Four-Coordinate Iron(II) Spin Crossover Complex. J. Am. Chem. Soc. 2013, 135, 19083-19086. [CrossRef]

19. Feng, X.; Mathonière, C.; Jeon, I.-R.; Rouzières, M.; Ozarowski, A.; Aubrey, M.L.; Gonzalez, M.I.; Clérac, R.; Long, J.R. Tristability in a Light-Actuated Single-Molecule Magnet. J. Am. Chem. Soc. 2013, 135, 15880-15884. [CrossRef] 
20. Mondal, A.K.; Goswami, T.; Misra, A.; Konar, S. Probing the Effects of Ligand Field and Coordination Geometry on Magnetic Anisotropy of Pentacoordinate Cobalt(II) Single-Ion Magnets. Inorg. Chem. 2017, 56, 6870-6878. [CrossRef]

21. Mondal, A.K.; Jover, J.; Ruiz, E.; Konar, S. Quantitative Estimation of Ising-Type Magnetic Anisotropy in a Family of $\mathrm{C}_{3}$-Symmetric Co ${ }^{\mathrm{II}}$ Complexes. Chem. Eur. J. 2017, 23, 12550-12558. [CrossRef]

22. Goómez-Coca, S.; Cremades, E.; Aliaga-Alcalde, N.; Ruiz, E. Mononuclear Single-Molecule Magnets: Tailoring the Magnetic Anisotropy of First-Row Transition-Metal Complexes. J. Am. Chem. Soc. 2013, 135, 7010-7018. [CrossRef] [PubMed]

23. Yao, X.-N.; Du, J.-Z.; Zhang, Y.-Q.; Leng, X.-B.; Yang, M.-W.; Jiang, S.-D.; Wang, Z.-X.; Ouyang, Z.-W.; Deng, L.; Wang, B.-W.; et al. Two-Coordinate Co(II) Imido Complexes as Outstanding Single-Molecule Magnets. J. Am. Chem. Soc. 2017, 139, 373-380. [CrossRef]

24. Mondal, A.K.; Mondal, A.; Dey, B.; Konar, S. Influence of the Coordination Environment on Easy-Plane Magnetic Anisotropy of Pentagonal Bipyramidal Cobalt(II) Complexes. Inorg. Chem. 2018, 57, 9999-10008. [CrossRef]

25. Jurca, T.; Farghal, A.; Lin, P.H.; Korobkov, I.; Murugesu, M.; Richeson, D.S. Single-Molecule Magnet Behavior with a Single Metal Center Enhanced through Peripheral Ligand Modifications. J. Am. Chem. Soc. 2011, 133, 15814-15817. [CrossRef] [PubMed]

26. Murrie, M. Cobalt(II) single-molecule magnets. Chem. Soc. Rev. 2010, 39, 1986-1995. [CrossRef] [PubMed]

27. Mondal, A.K.; Jover, J.; Ruiz, E.; Konar, S. Single-ion magnetic anisotropy in a vacant octahedral Co(II) complex. Dalton Trans. 2019, 48, 25-29. [CrossRef]

28. Zadrozny, J.M.; Long, J.R. Slow magnetic relaxation at zero field in the tetrahedral complex $\left[\mathrm{Co}(\mathrm{SPh})_{4}\right]^{2-}$. J. Am. Chem. Soc. 2011, 133, 20732-20734. [CrossRef]

29. Novikov, V.V.; Pavlov, A.A.; Nelyubina, Y.V.; Boulon, M.E.; Varzatskii, O.A.; Voloschin, Y.Z.; Winpenny, R.E.P. A trigonal prismatic mononuclear cobalt(II) complex showing single-molecule magnet behavior. J. Am. Chem. Soc. 2015, 137, 9792-9795. [CrossRef]

30. Vaidya, S.; Upadhyay, A.; Singh, S.K.; Langley, S.K.; Walsh, J.P.S.; Murray, K.S.; Rajaraman, G.; Shanmugam, M. A synthetic strategy for switching the single ion anisotropy in tetrahedral cobalt(II) complexes. Chem. Commun. 2014, 51, 3739-3742. [CrossRef]

31. Rigamonti, L.; Bridonneau, N.; Poneti, G.; Tesi, L.; Sorace, L.; Pinkowicz, D.; Jover, J.; Ruiz, E.; Sessoli, R.; Cornia, A. A Pseudo-Octahedral Cobalt(II) Complex with Bispyrazolylpyridine Ligands Acting as a Zero-Field Single-Molecule Magnet with Easy Axis Anisotropy. Chem. Eur. J. 2018, 24, 8857. [CrossRef] [PubMed]

32. Vallejo, J.; Castro, I.; Garcia, R.R.; Cano, J.; Julve, M.; Lloret, F.; Munno, G.D.; Wernsdorfer, W.; Pardo, E. Field-Induced Slow Magnetic Relaxation in a Six-Coordinate Mononuclear Cobalt(II) Complex with a Positive Anisotropy. J. Am. Chem. Soc. 2012, 134, 15704-15707. [CrossRef] [PubMed]

33. Mondal, A.K.; Khatua, S.; Tomar, K.; Konar, S. Field-Induced Single-Ion-Magnetic Behavior of Octahedral $\mathrm{Co}^{\mathrm{II}}$ in a Two-Dimensional Coordination Polymer. Eur. J. Inorg. Chem. 2016, 3545-3552. [CrossRef]

34. Kieber-Emmons, M.T.; Annaraj, J.; Seo, M.S.; Van Heuvelen, K.M.; Tosha, T.; Kitagawa, T.; Brunold, T.C.; Nam, W.; Riordan, C.G. Identification of an "end-on" nickel-superoxo adduct, $\left[\mathrm{Ni}(\mathrm{tmc})\left(\mathrm{O}_{2}\right)\right]^{+}$. J. Am. Chem. Soc. 2006, 128, 14230-14231. [CrossRef] [PubMed]

35. Cho, J.; Woo, J.; Nam, W. An "End-On" Chromium(III)-Superoxo Complex: Crystallographic and Spectroscopic Characterization and Reactivity in $\mathrm{C}-\mathrm{H}$ Bond Activation of Hydrocarbons. J. Am. Chem. Soc. 2010, 132, 5958-5959. [CrossRef] [PubMed]

36. Cho, J.; Sarangi, R.; Annaraj, J.; Kim, S.Y.; Kubo, M.; Ogura, T.; Solomon, E.I.; Nam, W. Geometric and electronic structure and reactivity of a mononuclear "side-on" nickel(III)-peroxo complex. Nat. Chem. 2009, 1, 568. [CrossRef]

37. Annaraj, J.; Suh, Y.; Seo, M.S.; Kim, S.O.; Nam, W. Mononuclear nonheme ferric-peroxo complex in aldehyde deformylation. Chem. Commun. 2005, 36, 4529-4531. [CrossRef] [PubMed]

38. Cahier, B.; Perfetti, M.; Zakhia, G.; Naoufal, D.; ElKhatib, F.; Guillot, R.; Rivière, E.; Sessoli, R.; Barra, A.L.; Guihéry, N.; et al. Magnetic Anisotropy in Pentacoordinate $\mathrm{Ni}^{\mathrm{II}}$ and $\mathrm{Co}^{\mathrm{II}}$ Complexes: Unraveling Electronic and Geometrical Contributions. Chem. Eur. J. 2017, 23, 3648-3657. [CrossRef] 
39. Cui, H.-H.; Wang, J.; Chen, X.-T.; Xue, Z.-L. Slow magnetic relaxation in five-coordinate spin-crossover cobalt(II) complexes. Chem. Commun. 2017, 53, 9304-9307. [CrossRef]

40. Alvarez, S.; Alemany, P.; Casanova, D.; Cirera, J.; Llunell, M.; Avnir, D. Shape maps and polyhedral interconversion paths in transition metal chemistry. Coord. Chem. Rev. 2005, 249, 1693-1708. [CrossRef]

41. Addison, A.W.; Rao, T.N.; Reedijk, J.; Vanrijn, J.; Verschoor, G.C. Synthesis, structure, and spectroscopic properties of copper(II) compounds containing nitrogen-sulphur donor ligands; the crystal and molecular structure of aqua[1,7-bis(N-methylbenzimidazol-2'-yl)-2,6-dithiaheptane]copper(II) perchlorate. J. Chem. Soc. Dalton Trans. 1984, 7, 1349-1356. [CrossRef]

42. Mabbs, F.E.; Machin, D.J. Magnetism and Transition Metal Complexes; Dover Publications: Mineola, NY, USA, 2008.

43. Chilton, N.F.; Anderson, R.P.; Turner, L.D.; Soncini, A.; Murray, K.S. PHI: A powerful new program for the analysis of anisotropic monomeric and exchange-coupled polynuclear $\mathrm{d}$ - and $\mathrm{f}$ block complexes. J. Comput. Chem. 2013, 34, 1164-1175. [CrossRef] [PubMed]

44. Atanasov, M.; Aravena, D.; Suturina, E.; Bill, E.; Maganas, D.; Neese, F. First principles approach to the electronic structure, magnetic anisotropy and spin relaxation in mononuclear $3 \mathrm{~d}$-transition metal single molecule magnets. Coord. Chem. Rev. 2015, 289, 177-214. [CrossRef]

45. Bartolome, J.; Filoti, G.; Kuncser, V.; Schinteie, G.; Mereacre, V.; Anson, C.E.; Powell, A.K.; Prodius, D.; Turta, C. Magnetostructural correlations in the tetranuclear series of $\{\mathrm{Fe} 3 \mathrm{LnO} 2\}$ butterfly core clusters: Magnetic and Mössbauer spectroscopic study. Phys. Rev. B Condens. Matter Mater. Phys. 2009, 80, 014430. [CrossRef]

46. Lin, P.H.; Burchell, T.J.; Ungur, L.; Chibotaru, L.F.; Wernsdorfer, W.; Murugesu, M. A Polynuclear Lanthanide Single-Molecule Magnet with a Record Anisotropic Barrier. Angew. Chem. Int. Ed. 2009, 48, 9489-9492. [CrossRef] [PubMed]

47. Gamer, M.T.; Lan, Y.; Roesky, P.W.; Powell, A.K.; Clerac, R. Pentanuclear Dysprosium Hydroxy Cluster Showing Single-Molecule-Magnet Behavior. Inorg. Chem. 2008, 47, 6581-6583. [CrossRef] [PubMed]

48. Xu, G.F.; Wang, Q.L.; Gamez, P.; Ma, Y.; Clerac, R.; Tang, J.; Yan, S.P.; Cheng, P.; Liao, D.Z. A promising new route towards single-molecule magnets based on the oxalate ligand. Chem. Commun. 2010, 46, 1506-1508. [CrossRef]

49. Mondal, A.K.; Parmar, V.S.; Konar, S. Modulating the Slow Relaxation Dynamics of Binuclear Dysprosium(III) Complexes through Coordination Geometry. Magnetochemistry 2016, 2, 35. [CrossRef]

50. Cole, K.S.; Cole, R.H. Dispersion and Absorption in Dielectrics I. Alternating Current Characteristics. J. Chem. Phys. 1941, 9, 341-351. [CrossRef]

51. Guo, Y.-N.; Xu, G.-F.; Guo, Y.; Tang, J. Relaxation dynamics of dysprosium(III) single molecule magnets. Dalton Trans. 2011, 40, 9953-9963. [CrossRef]

52. Colacio, E.; Ruiz, J.; Ruiz, E.; Cremades, E.; Krzystek, J.; Carretta, S.; Cano, J.; Guidi, T.; Wernsdorfer, W.; Brechin, E.K. Slow magnetic relaxation in a Co(II)-Y(III) single-ion magnet with positive axial zero-field splitting. Angew. Chem. Int. Ed. 2013, 52, 9300-9304. [CrossRef]

53. Campbell, V.E.; Guillot, R.; Rivière, E.; Brun, P.-T.; Wernsdorfer, W.; Mallah, T. Subcomponent Self-Assembly of Rare-Earth Single-Molecule Magnets. Inorg. Chem. 2013, 52, 5194-5200. [CrossRef] [PubMed]

54. Ungur, L.; Thewissen, M.; Costes, J.-P.; Wernsdorfer, W.; Chibotaru, L.F. Interplay of Strongly Anisotropic Metal Ions in Magnetic Blocking of Complexes. Inorg. Chem. 2013, 52, 6328-6337. [CrossRef] [PubMed]

55. Mondal, A.K.; Jena, H.S.; Malviya, A.; Konar, S. Lanthanide-Directed Fabrication of Four Tetranuclear Quadruple Stranded Helicates Showing Magnetic Refrigeration and Slow Magnetic Relaxation. Inorg. Chem. 2016, 55, 5237-5244. [CrossRef] [PubMed]

56. Kahn, O. Molecular Magnetism; VCH Publishers: Weinheim, Germany, 1993.

57. Sheldrick, G.M. SHELXTL Program for the Solution of Crystal of Structures; University of Göttingen: Göttingen, Germany, 1993.

58. Sheldrick, G.M. SHELXL 97, Program for Crystal Structure Refinement; University of Göttingen: Göttingen, Germany, 1997.

59. Spek, A.L. Single-crystal structure validation with the program PLATON. J. Appl. Crystallogr. 2003, 36, 7-13. [CrossRef] 
60. Farrugia, L.J. WinGX suite for small-molecule single-crystal crystallography. J. Appl. Crystallogr. 1999, 32, 837-838. [CrossRef]

61. Neese, F. The ORCA program system. Wiley Interdiscip. Rev. Comput. Mol. Sci. 2012, 2, 73-78. [CrossRef] 